\title{
ADOPTION AND USE OF DISPUTE RESOLUTION PROCEDURES IN THE NONUNION WORKPLACE ${ }^{1}$
}

\author{
Alexander J.S. Colvin \\ Dept. of Labor Studies and \\ Industrial Relations \\ Pennsylvania State University \\ University Park, PA 16802-2800 \\ (814) 865-0754 (ph) \\ (814) 863-9545 (fax) \\ ajc10@psu.edu
}

\footnotetext{
${ }^{1}$ The author would like to thank Harry Katz, Rose Batt, Katherine Stone, David Lipsky, David Lewin, and anonymous referees for helpful comments. My particular thanks are owed to the employees of TRW who gave generously of their valuable time for the interviews for this research project. Any mistakes, errors, or omissions are, however, my responsibility alone.
} 


\section{$\underline{\text { Introduction }}$}

This paper investigates the adoption, structure, and function of dispute resolution procedures in the nonunion workplace. Whereas grievance procedures in unionized workplaces have been an important area of study in the field of industrial relations, research on dispute resolution procedures in nonunion workplaces has lagged behind. As a result, our knowledge of the development of nonunion procedures remains relatively limited. Similarly, with a few noteworthy exceptions (e.g. Lewin, 1987, 1990), our knowledge of workplace grievance activity is almost entirely based on research conducted in unionized settings. Given the major differences in the institutional contexts of union and nonunion workplaces in the United States, existing ideas about workplace dispute resolution developed in the unionized setting will likely require significant modification in order to understand dispute resolution procedures and activity in the nonunion workplace. Issues relating to dispute resolution in the nonunion workplace are of increasing importance to public policy given the combination of continued stagnation in levels of union representation and mounting concerns over rising levels of employment litigation in the courts. Knowing what nonunion dispute resolution procedures look like and how they function will help answer the question of what role these procedures may play in the future governance of the workplace.

In the contemporary unionized workplace, issues of the adoption and structure of grievance procedures spark relatively little controversy. Development and diffusion of union grievance procedures dates to the period of the 1940's War Labor Board and the post-War consolidation of stable collective bargaining. The structure of union grievance procedures has exhibited remarkable stability since that period, with virtually all current unionized workplaces 
having multi-stage grievance procedures culminating in arbitration (Eaton and Keefe, 1999). By contrast, nonunion dispute resolution procedures vary widely in both their adoption and structure. As many as half of all nonunion workplaces continue to lack any formal procedures for the resolution of employee complaints (Feuille and Chachere, 1995). Among workplaces that do feature formal dispute resolution procedures, these procedures vary in basic features such as, who is the final decision-maker under the procedure, whether employees are permitted representation, what complaints can be brought under the procedure, and what criteria are used to decide disputes (Feuille and Delaney, 1992; Feuille and Chachere, 1995).

An initial issue that needs to be addressed with regard to nonunion procedures is what factors shape the diversity in the structures that are used to resolve disputes in the nonunion workplace. As with other areas of industrial relations and human resource practices, environmental pressures and human resource strategies provide two broad categories of factors that may influence the development of nonunion dispute resolution procedures (Barringer and Milkovich, 1998). Among environmental pressures, concerns about workplace disputes giving rise to litigation and the desire to avoid unionization by providing workers with a mechanism for resolving complaints have both been suggested as possible motivations for nonunion organizations to introduce procedures (Feuille and Delaney, 1992). Some have argued, however, that union substitution no longer plays a major role in the introduction of nonunion procedures due to declining unionization levels and reduced fear of organizing activity (Feuille and Delaney, 1992). Others have suggested that the extent of actual litigation pressures on organizations are also often exaggerated, though fear of litigation may provide an important rhetorical device in convincing managers to adopt procedures as an appropriate organizational 'best practice' 
(Edelman, 1990; Edelman, Abraham, and Erlanger, 1992; Edelman, Uggen, and Erlanger, 1999). An alternative category of explanations suggest that nonunion procedures are adopted as part of human resource strategies that emphasize fostering positive relations between employees and management. Arguments from the perspective of organizational justice theory suggest that by providing greater procedural and distributive justice in decision-making, nonunion procedures may reduce turnover and foster greater employee commitment and effort (Olson-Buchanan 1996). In addition to the question of what is the respective importance of environmental pressures and human resource strategies in the adoption of procedures, an additional question to be addressed is whether there is any interaction between these factors in how procedures are developed.

A second set of issues relating to nonunion dispute resolution procedures concern how they are used by employees and what is their function in the workplace. The traditional image of nonunion procedures was that they were little used by employees due to their deficiencies in the area of due process and were largely ineffective as workplace institutions (Slichter, Healy, and Livernash, 1960). More recent research has found examples of nonunion procedures with more regular employee usage, though at levels well below that of typical union grievance procedures (Lewin, 1987, 1990). In addition to differences in usage levels, the way in which nonunion procedures function may differ significantly from union grievance procedures. In particular, the absence of the institutionalized presence of the union in representing employees means that in a nonunion procedure employees are much more dependent on the goodwill of management in resolving complaints. The question of how nonunion procedures function in practice is closely linked to the issue of what impact these procedures have on the operation of the workplace. For 
unionized workplaces, persistent high grievance rates have been seen as a major part of embedded high conflict patterns of industrial relations, interfering with the operations of the workplace and reducing productivity (Kochan, Katz, and McKersie, 1994). By contrast, for nonunion procedures the initial question is not excessive conflict, but rather whether the procedures have enough of an impact on the management of the workplace to make any real difference for employees.

In this paper, I investigate these questions of the formation and function of nonunion dispute resolution procedures through a case study of the procedures adopted at the multidivisional manufacturing firm TRW. TRW provides a useful case for investigating the possible direction of development of nonunion procedures due to its relatively extensive set of procedures for its nonunion employees. Concerning the adoption of procedures, the results of the case study will provide support for the importance of both environmental pressures and human resource strategies. Furthermore, it will suggest that these are not simply alternative explanations for the adoption of procedures, but rather operate as complimentary factors that interact in shaping the structure of nonunion procedures. On the issue of the usage and function of nonunion procedures, the results of the case study suggest that employees do use at least this type of more developed nonunion procedures, but that concerns remain as to due process limitations in the operation of the procedures. At the same time, the procedures do appear to have had some significant impacts on the operation of the workplace. Most notably, procedures in some instances led to increased negotiated resolution of workplace disputes and modification of existing practices or procedures, despite features in the design of the procedures directed at limiting this type of outcome. Lastly, the case study results reveal a major division between 
white-collar and blue-collar employee groups in both the development and operation of

procedures. The contrasts found between these two groups indicate the need to be careful about making generalizations about the nonunion workforce, which can be characterized by high degrees of diversity in employment conditions and outcomes.

\section{Methodology}

As noted above, this paper investigates the adoption and use of nonunion dispute resolution procedures through a case study of procedures at the multidivisional American manufacturing company, TRW. In the context of dispute resolution, TRW provides a useful case for understanding the development of nonunion procedures due to the relatively extensive and elaborate nature of the procedures that the company has adopted. Rather than being a typical case, it was selected as a 'best practice' case in order to investigate the impact of nonunion procedures in an organizational setting where particularly strong efforts have been made to ensure the widespread adoption and use of the procedures. This is not to suggest or advocate that organizations should necessarily adopt the practices that are described here, but rather that we can better evaluate the possibilities and limitations of nonunion procedures from a 'best practice' case than from a case with less extensive procedures. By analogy, past research was able to learn much about the impact of employee involvement in the workplace from studying GM's innovative Saturn division (e.g. Rubinstein and Kochan 2001) and about employee ownership from the unusually active worker ownership structure used at the Rath packing company (Hammer and Stern, 1986) not because these were typical cases, but rather because they were 'best practice' cases that provided strong examples of the phenomena being investigated. 
The primary data sources for the case study presented in this paper are interviews conducted by the author at the company in 1997-98 and examination of documents relating to the procedures. Individual interviews were one to one-and-a-half hours and followed a semistructured format. Primary interview subjects included human resource managers at the corporate, divisional, and plant level, and in-house employment and labor law counsel. Secondary information sources included descriptions of the company's procedures and experience with their usage that have been presented by TRW managers at conferences (e.g. Boxer 2000) and a profile of dispute resolution procedures at TRW was included in a 1997 General Accounting Office (GAO) report as one of five private sector companies providing leading examples of the adoption of nonunion dispute resolution procedures (GAO, 1997).

The primary focus in the research was on the management side. The reason for this focus was that management decision-making was central to the research questions being investigated; in particular decisions of management determined the adoption of the procedures, the structure of the procedures, and how they were operated. Although additional perspectives on the issues examined were obtained from union and plaintiff attorney sources, the primary focus on the management side is a limitation of the research emphasis that should be recognized. A more general research caution is inherent in the use of a 'best practice' case methodology. As is the case for this study, in following a 'best practice' case methodology the researcher selects a research site to represent a strong example of a particular phenomenon. The danger then becomes that the researcher will excessively identify with the interests of the group or organization being studied and this will in turn influence the research findings. This is not to suggest that what the researcher views as 'best practice' cases should not be studied, but rather 
that the researcher needs to be aware of and recognize potential biases. In the present case, as a researcher I approached this case study with the recognition that I was examining what I viewed as likely a best case scenario for nonunion procedures. With that recognition in mind, the case study was written with an effort to identify both the potential weaknesses and the strengths of the company's procedures and with this initial caution to readers that they are reading about a case that was deliberately selected as a potential 'best practice' case for the phenomenon in question.

\section{Case Background}

The diversified manufacturing company TRW has occupied a prominent role in American industrial relations history and research. During the earlier part of the $20^{\text {th }}$ century, under its former name of Thompson Products, the firm was one of the leading exemplars of the "welfare capitalist" movement among American companies. Despite organizing efforts by the United Auto Workers during the 1930's and 40's, only a few of the company's plants became unionized during the period of expansion of unionization following passage of the Wagner Act. In his landmark study of the survival and continuation of welfare capitalism during the post-war period, Modern Manors, Sanford Jacoby (1997) uses Thompson Products, along with Eastman Kodak and Sears, as a critical case study of a company that continued to follow this management philosophy during an era when it was thought to have disappeared from the landscape of American business. Thompson Products' ability to maintain its predominantly nonunion status during the post-war period was not due solely to the benefits offered to employees by welfare capitalism. Jacoby (1997) notes that, unlike Eastman Kodak and Sears, Thompson Products was subject to intensive union organizing, to which the company often responded with more heavy- 
handed tactics. Although unions succeeded in organizing some TRW plants during the post-war period, by the 1990's, only three or four of the company's American plants were unionized.

The current TRW is a diversified manufacturing company, headquartered in Cleveland, Ohio. Organizationally, it is divided into two business groups. One is the Automotive group, which accounts for $60 \%$ of total sales. Auto parts were the traditional center of the company's business, though it has remained dynamic in this area in recent years through expansion into new product areas such as air bags. The other major group in the firm is TRW's Space, Defense and Information Technology business group, which contains two units: space and defense; and systems integration. In sharp contrast to the more traditional manufacturing setting of the Automotive group, the Space, Defense and Information Technology (SDIT) group produces highly sophisticated products with a predominantly professional workforce. Among, the space and defense unit's primary products are commercial and military satellites. In addition, it is the primary contractor for such major defense contracts as the airborne laser being produced for the U.S. Air Force. The other major unit within this group is systems integration, which provides management and information system services for complex operations, such as a major government research projects.

An important factor in understanding developments at TRW is the values and human resource orientation of the company's management. During the 1930's and 40's Thompson Products' retention of welfare capitalist policies was heavily influenced by the employee relations values of the company's president, Frederick C. Crawford (Jacoby, 1997). This orientation continued during the 1960 's, when the company began experimenting with new behavioral science concepts in the management of its workforce, such as innovative 
compensation and selection systems. In addition, in 1977 the company opened a new nonunion team-concept plant in which employees were assigned to teams rather than specific jobs and compensation was all-salaried based on a pay-for-knowledge system (Kochan, Katz, and McKersie, 1994). These human resource policies were developed in the context of the company's continuing commitment to avoiding unionization. In particular, the innovative practices were concentrated in the company's newer nonunion facilities and not extended to its few unionized facilities. More recently, the company's current human resource management orientation is reflected in strong public advocacy by its management of such policies as gainsharing, pay-for-productivity and employee involvement (Daily Labor Report, 1994 DLR 13 d11). It is also noteworthy that the executive vice-president of human resources at TRW is a member of the firm's executive committee, indicating the relatively strong role of human resource management considerations in the firm's decision-making.

Dispute resolution procedures formed part of the high commitment human resource policies introduced at TRW facilities in the 1960's and 70's. These procedures initially consisted of provisions for written complaints to be filed with and reviewed by management. These procedures primarily provided a more formal and systematic structure for management review of employee concerns, rather than a more independent process of dispute resolution. In addition, committees composed of employees were established in plants to bring complaints of general concern to management. Although providing a mechanism for raising employee grievances, a weakness of these procedures was that they did not provide a structure for the resolution of disputes beyond the normal management decision-making process. However, during the 1990's a series of factors led to the development of more complex dispute resolution 
procedures that afforded greater independence from the management chain-of-command in the adjudication of employee grievances.

Rather than a single process, development of nonunion procedures at TRW in the 1990's actually involved two distinct processes that led to the introduction of two different types of procedures, peer review procedures and nonunion arbitration procedures. Under peer review procedures, employees who are peers of the employee filing the complaint sit on a panel that decides the grievance. By contrast under the nonunion arbitration procedures a neutral arbitrator hears and decides claims by employees against the company concerning violation of employee legal rights. Although there were common elements in the development of these procedures, the development and introduction of each procedure involved a distinct decision-making process in response to separate pressures and motivations. Furthermore, once adopted the peer review and nonunion arbitration procedures retained distinctions in their operation, usage, and functions. For this reason, in the subsequent sections the development and use of the two types of procedure will be examined separately, beginning with the peer review procedures, then turning to the nonunion arbitration procedures. In this respect, the procedures serve as an embedded unit of analysis within the organizational case that permits comparing and contrasting two different processes of procedure development within the same firm.

\section{Peer Review Procedures}

In the early 1990's, TRW's Vehicle Safety Systems division introduced peer review for the first time into dispute resolution procedures in the company. Vehicle Safety Systems (VSSI) is a division of the automotive business group. Its primary products are air bags and seat belts. 
This is a relatively new product area for the company, with the initial part of the division entering the company through a 1984 acquisition. With the expansion of the use of air bags in automobiles, the division grew rapidly from a $\$ 2$ million business in 1984 to an over $\$ 2$ billion business by the late 1990's. All of VSSI's American plants are nonunion and are generally recently constructed facilities, with relatively young workforces. The total workforce of the division is 16,000 employees, half of whom are located in the United States, with the remainder spread across plants in other countries, including Mexico, Canada, and Germany.

Introduction of a peer review procedure was first proposed at VSSI during the early 1990's based on a series of interrelated reasons why the practice would be advantageous to the division. The first rationale was that peer review would serve as a "counter-defensive" move to avoid VSSI's plants becoming a target for unionization. Although VSSI had managed to avoid unionization of its American plants, with the continued strength of the UAW in the industry its plants remained a potentially attractive target for organizing. The perception of managers in the division was that their employees were aware of what employment conditions were like in the unionized plants in the auto industry. As a consequence, management actively monitored what was going on in the unionized sector of the industry to ensure that the wages and conditions of employment in VSSI's nonunion plants were roughly comparable. Peer review was offered as a component of that strategy of union substitution, which would provide a better substitute for union grievance procedures than the division's existing complaint procedures. A closely related rationale offered for the introduction of peer review was that it would respond to the expectations of the division's workforce. As noted earlier, employees in the division are relatively young, averaging 25-35 years of age in most plants. Management perceived these employees as 
expecting a high involvement, team-oriented culture in the workplace, what one manager described as the "video generation who want a say in the business." Peer review was proposed as a way to respond to these perceived employee expectations that would complement related human resource practices such as performance- and group-based compensation and self-directed work teams. The complimentarity with VSSI's overall high commitment human resource strategy was the third rationale offered for the introduction of peer review. Peer review was advocated as being in keeping with the "spirit of a modern company" that TRW was seeking to achieve in its human resource strategy. Peer review was offered as a new "best practice" in the area of dispute resolution procedures, which would be appropriate for TRW to adopt.

It is worth noting that although peer review procedures were adopted in other companies, most prominently at General Electric, in the 1970's, they were not part of the initial set of human practices adopted when VSSI's first facilities were opened in the mid-1980's. Instead, peer review first came under consideration as a new type of best practice in the 1990's. This reflects the significant lag times often involved in the diffusion and adoption of new practices, a factor important to consider in examining the causes of change in employment relations. In addition, it reflects the importance of changes in the set of options for behavior under consideration by management. Taking a strategic choice view of employment relations (Kochan, Katz, and McKersie, 1994) suggests that to understand change it is necessary to consider the specific alternatives under consideration at the relevant point in time. The environmental factors that ultimately led to the introduction of peer review were already present in the 1980's. However it was only in the 1990's that VSSI management brought into consideration the option of introducing peer review as a new best practice that would help avoid the environmental threat of 
union organizing, respond to the expectations of its workforce, and complement its other human resource practices.

Although peer review was presented as a policy that complimented VSSI's human resource strategy, its initial proposal met resistance from both senior and lower-level line managers. In particular, line managers were concerned about the prospect of having to justify their actions to employees on the peer review panels. A key factor in convincing management to adopt peer review was the assurance offered to line managers that human resource managers would be there to provide support to line managers when they went into peer review. However concerns remained and were exacerbated when the first peer review hearing resulted in the overturning of a line manager's decision. Although this decision exacerbated line management concerns about peer review, it ultimately proved fortuitous in helping establish early on to employees that management would respect the decisions of the panels, even if unfavorable.

The peer review procedure was introduced at VSSI in 1992 as an additional procedure to which employee disputes could be taken to on top of existing open door policies at plants. Usage of peer review was restricted, however, to employee complaints about final warning or termination decisions, excluding terminations due to elimination of the employee's job or work reduction. Peer review panels consist of five members, two managers and three peer employees. A new panel is formed for each appeal. The definition of peer is grievant specific, so if the employee is a production worker, the peer employee panelists will be selected from all eligible production workers in the plant. In order to serve on a peer review panel, an employee must have been employed for at least one year, not be under corrective counseling, and not have received disciplinary action or corrective counseling in the past year. Additional exclusions from 
panel membership include: family members of the grievant; anyone in the chain of command of the grievant; members of human resources; and "persons who have a vested interest and/or conflict of interest in the outcome of the meeting."

The members of the panel are chosen at random from the pool of eligible peer employees and managers by the grievant. The employee first picks four names from the pool of eligible managers, chooses two of the managers picked to serve as panel members, then selects one as an alternate, and discards one name. Then the employee picks five names from the pool of eligible peer employees, chooses three employees to serve as panel members, selects one as an alternate, and discards one name. Service on the peer review panels is voluntary and panelists may not serve on two consecutive peer review panels. If a grievant requests, one of the panelists may be chosen from a pool specifically composed of members of a protected minority class of which the grievant is a member. As a general rule, there must be at least 15 members in each pool from which panelists are chosen. If there are not enough members in any group at a facility, employees from other locations may be included in the pool to ensure sufficient numbers. This is a particularly concern where there are insufficient numbers of employees in a protected minority class to ensure representation on the panel of peers of the same racial or ethnic group as a minority complainant.

For each panel, a human resources representative serves as a "facilitator" (Schwarz, 1994). The role of the facilitator is to handle the administration of the procedure, organize meetings, maintain files, and provide assistance to the panel. In addition to organizational and record keeping duties, the facilitator has a more substantive role in the procedure in meeting with the grievant and supervisor to explain the procedure, determining any conflict of interest 
questions in the panel selection, and gathering any data or information requested by the panel. The importance of the role of the facilitator is enhanced by the instruction in the procedure that they "may be called upon to provide policy interpretation and general factual information concerning precedents, but he/she is not expected to give detailed information regarding other specific corrective actions, appeals, or precedents." Given this significant role of the facilitator in the peer review procedure, only senior human resources representatives are allowed to perform this function. In addition, any human resource representative involved in the decision under appeal is not allowed to act as the facilitator.

Peer review proceedings are commenced by the employee filing a peer review request form stating whether it is a final warning or a termination case, the nature of the employee's concern, and the company policy in question. Requests for peer review must be filed within three working days of the final warning or termination decision being appealed. Following the filing of the request form with human resources, a panel will be convened in a time not to exceed 45 days from the request.

Prior to the hearing, peer review panelists are given a day of training consisting of instruction on the procedure and on the conduct of hearings. A major focus in the training is to emphasize the confidentiality of the procedure. Management had strong initial concerns that employees would be reluctant to use peer review if they thought that confidential information about them would be spread around the plant by the panelists. In practice, this has not been a problem with the panels. During the training period, the panels are also asked to select their own panel leader. The panel leader is responsible for chairing the hearing and making procedural decisions on issues such as the calling of witnesses. The facilitators generally recommend that a 
peer employee lead the panel and this is the usual practice.

At the commencement of the peer review hearing, the human resources facilitator introduces the subject of the complaint. The employee is then given the opportunity to present his/her case, including presenting any documents or witnesses that support his/her case. The employee's presentation may be oral, written, or both, however no internal or external employee representative is permitted to participate in the hearing. Following the employee's presentation, the supervisor who made the decision being challenged is given an opportunity to justify his/her actions, including any documents or materials supporting his/her position. The supervisor must present his/her case on his/her own, also without assistance of a representative. The panel can cross-examine witnesses presented by the employee or the supervisor, as well as call any additional witnesses they want to hear from. The panel is entitled to examine company files and records, as well as to "seek advice from experts within the Company regarding policy interpretation, etc."

Following the presentations of the employee and supervisor and when all information the panelists wish to review has been heard, the employee and supervisor are excused from the hearing room and the panel deliberates. During training, the panelists are instructed that they are limited to reviewing the application of company policies and cannot change policy. However, the procedures also note that policies are only guidelines and cannot cover every situation. Thus, panelists are also instructed that "a common sense approach must be used by the panel members in determining the final outcome." Then, after discussion of the information presented at the hearing, the panel makes its decision by secret ballot. The panel leader conducts the secret ballot, with all panelists voting. Ballots are opened one by one until a majority of votes are cast 
to accept or reject the employee's appeal. Remaining ballots are not opened and all ballots are destroyed after the counting of the votes. The unusual procedure of not opening the remaining ballots once a result is reached protects panelist independence by reducing the possibility of determining which way any individual panel member voted - e.g. if four of the five panel members admitted to voting for or against an appeal it would be possible to identify the dissenting panel member on a 4-1 majority vote. However, in some cases it prevents the employee from knowing what the final vote count was on the panel - e.g. if the first three votes opened were to deny the appeal, the employee will not be able to find out if the final vote count would have been 3-2, 4-1, or 5-0. If an appeal of a final warning is accepted by the panel, the warning is removed. If an appeal of a termination is accepted by the panel, the termination is reversed and the employee reinstated with retroactive pay and benefits.

Although the first decision from a VSSI peer review panel accepted the employee's appeal, the majority of subsequent decisions were in favor of upholding the supervisor's decision. From 1992 to 1997 , only 10 of 160 employees who took cases to peer review were successful. The cases where employees were successful in appealing to peer review panels often involved failures of management to follow the exact procedural details of their own rules, such as the form and timing of warnings, rather than the content of the complainant's conduct. The division intentionally limited the panels to considering whether or not company policies were correctly applied, though the human resource managers expressed some surprise at the degree to which employees on the panels have held management to the letter of the rules in the conduct of discipline and terminations. This may reflect a reality that if peer employees are placed in a structure where the only basis on which they can overturn management decisions is for lack of 
compliance with company rules, they then turn to less flexible interpretations of management behavior under the rules in order to obtain the leverage necessary to accept appeals.

Although employees have not had a high success rate at hearings, peer review may have a broader impact on the behavior of line and human resources managers. Given the possibility of having to justify their decisions to a peer review panel, managers reported having to be more careful in making termination or final warning decisions. Peer review is thus seen as having an indirect effect on the behavior of managers in making them more accountable and keeping them on their toes.

\section{Nonunion Arbitration Procedures}

Although both represent alternatives to traditional management review in dispute resolution, the development of nonunion arbitration and peer review at TRW involved responses to different environmental pressures involving very different groups of employees. In contrast to the union substitution and human resource strategy motivations that led to the introduction of peer review in VSSI, the development of TRW's nonunion arbitration procedure was a response to changing patterns of employment litigation against the firm. In addition, whereas peer review was first introduced in the auto parts section of the company, nonunion arbitration was developed primarily in response to events in TRW's Space, Defense, and Information Technology (SDIT) group.

In contrast to the traditional manufacturing plants of the automotive business group, the SDIT group operates extremely high technology facilities employing highly skilled workers. Among the best known of the products of the group's space and defense unit was the NASA 
probe Pioneer 10, the first probe to reach Jupiter and the first human made spacecraft to escape the gravity of the solar system. On a less ethereal front, the group is building the first tactical lasers for the Army and the Air Force, and is a leader in the area of battlefield information systems. This type of product leads to a strikingly different production facility setting from traditional manufacturing. For instance, at the group's main "Space Park" location in Redondo Beach, California, one of the production labs is a single production facility in which around 150 engineers and scientists work on producing a single satellite at a time. In some respects, these facilities resemble a high technology version of a shipyard, with each product being worth millions of dollars and production occurring in an almost craft-like fashion. Overall, sixty percent of the group's workforce is classified as exempt professional and managerial employees.

Until the early 1990's TRW had experienced very little employment litigation. In part, this was likely due to the limited nature of exceptions to employment-at-will. However, a major additional factor was that the company gave employees effective lifetime employment, a practice reflective of the historical welfare capitalist philosophy of the firm. This effective lifetime employment policy was ruptured in the early 1990's when the SDIT group engaged in largescale layoffs in response to the contraction of the aerospace industry following the end of the Cold War. Although the contraction of the industry may have created the economic necessity for the layoffs, it also made their impact particularly hard for the affected employees. With the whole aerospace industry in contraction, many of the laid-off employees were unable to quickly find alternative employment. Given the inevitable questions of fairness surrounding the dismissal of large numbers of employees, particularly those who believed the company had promised them lifetime employment, a major surge in employment litigation followed the 
layoffs. The ability of employees to engage in litigation was enhanced by the expansion of substantive employment rights during the 1980's and early 1990's, particularly in California, which increased the willingness of plaintiff attorneys to take on employment cases. As one manager graphically described the situation, they were "laying off employees when employment lawyers were starting to advertise their services on billboards at the side of highways."

At the same time as these developments were increasing the pressures from employment litigation upon the company, changes in the law of arbitration provided new opportunities to use alternative dispute resolution procedures to avoid litigation. In the United States Supreme Court's landmark 1991 decision in Gilmer v. Interstate/Johnson Lane, 500 U.S. 20 (1991), the court had held for the first time that rights contained in employment statutes, in that specific case the Age Discrimination in Employment Act, could be subject to mandatory arbitration under an arbitration agreement. Although the following decade would be filled with decisions attempting to sort out the many implications of Gilmer, what the decision did for the first time was open the door to the possibility that companies could adopt nonunion arbitration procedures that would serve as an alternative to litigation through the courts for claims against them by their employees (Stone, 1996, 1999). One advantage of nonunion arbitration procedures was that the employer could design the type of procedure it desired to fit its organizational objectives. Perhaps most importantly though, arbitration provided a mechanism to avoid being subject to the uncertainties and potentially large damages of the jury system. Although a competent arbitrator might be quite willing to find against the company where the employee had a valid claim, the general perception among management was that arbitrators would not be likely to award the type of extremely high damage amounts designed to punish companies that juries occasionally awarded. 
Damages would also be further reduced by the potential for arbitration to occur much more quickly than litigation, thereby preventing damages from accruing to the same amounts as could happen during slower moving court proceedings.

Recognizing the potential impact of these developments, the group's labor and employment counsel wrote a memo to TRW's senior management suggesting that the recent Gilmer decision had opened the door to using a nonunion arbitration procedure to avoid litigation and resolve these disputes at much lower cost. Following the memo, a management team was put together at the corporate level to investigate the development of an alternative dispute resolution procedure to handle employment disputes that might lead to litigation. The team included representatives from legal, human resources, and communications departments and was led by a vice-president of human resources. The team spent six months, occupying its members virtually full-time, investigating the question of what dispute resolution policy to adopt.

During its investigations, a major dividing point emerged within the team over the question of how to make sure any agreement establishing a nonunion arbitration procedure was enforceable against employees. Legal department members of the team were concerned that an arbitration agreement had to be clearly enforceable to make sure of protecting the company against potential employment litigation. To do so, they proposed that employees be required to sign arbitration agreements, either at initial hiring or as a condition of receiving salary increases or stock options. Although the courts would likely enforce arbitration agreements without any such additional consideration for the agreement beyond continued employment, legal counsel recommended this more conservative approach, which had been followed by another aerospace company that had just introduced a nonunion arbitration procedure. The human resources 
members of the team were strongly opposed to this proposal. They argued that it would lead to the dispute resolution procedure being viewed as an anti-employee move, which would conflict with TRW's overall human resource strategy of enhancing employee commitment and involvement. In particular, they objected that whereas other companies might require employees to sign arbitration agreements to get bonuses and stock options, this was inconsistent with the philosophy of employment relations at TRW.

The decision on how to handle the problem of ensuring any procedure was binding and enforceable became the crucial stumbling block in TRW's development of its nonunion arbitration procedure. After nine months of debate, the issue eventually had to be resolved by the company's General Counsel and its Executive Vice-President of Human Resources, who sided with the view that the nature of the arbitration procedure had to be made consistent with TRW's overall human resource philosophy. The final design decision reached was that the nonunion arbitration procedure would be mandatory and binding on the company, but that it would be mandatory but non-binding for the employee. The employee would be required to take any legal dispute arising from employment through the arbitration procedure, however if the employee did not accept the arbitrator's decision they would be free to proceed to litigation. The decision to make the arbitration decisions non-binding for employees makes TRW's procedure virtually unique among nonunion arbitration procedures. Indeed, it is worth remembering that the key reason Gilmer led to the expansion of nonunion arbitration was that it allowed for the implementation of procedures that would produce binding arbitration awards, eliminating the possibility of taking statutory employment claims to litigation. Despite having been inspired to consider introducing a nonunion arbitration procedure as a result of Gilmer offering the 
possibility of using it to avoid rising litigation, this decision meant that TRW would be relinquishing one of the primary advantages of arbitration to employers.

With the issue of the nonbinding status of the procedure finally resolved, a company policy directive was issued for the implementation of the new dispute resolution procedures (TRW Human Resources Memorandum No. 10, January 1, 1995). Although the policy directive required the establishment of new procedures and set out basic features that had to be included in each procedure, the format of the actual procedures was left up to the individual divisions of the company. The use of a company directive allowing a degree of discretion to individual divisions reflects both the decentralized business group and divisional organization of TRW, as well as the diversity between different parts of the company. Under the directive, each division was required to establish a dispute resolution procedure covering: involuntary terminations that could form the basis for a claim in the courts; claims of discrimination or harassment based on protected status; and claims of constructive discharge. Individual divisions could provide that other types of disputes were covered by the procedure, but a number of types of disputes had to be excluded from coverage. The excluded categories included: benefit or pension claims; workers' compensation; unemployment compensation; claims by the company for injunctive relief; and "the establishment or modification of TRW's policies or procedures". Certain due process features had to be included in the procedures. Employees would have the right to representation by counsel. A basic entitlement to discovery of relevant documents and deposition of one individual for each side could be expanded on order from the arbitrator. Remedies equivalent to those available in court could be ordered by the arbitrator. The arbitrator would be required to provide a written decision stating a summary of the claims, the remedies 
ordered, and the reasons for the award. As had been decided, the decision of the arbitrator would be binding on the company, but not binding on the employee. However, the company reserved the right to introduce the arbitrator's decision as evidence in any subsequent litigation. Initially, the directive provided that the costs would be split, but that the employee's contribution would be capped at two days base pay. If the employee were successful, the company would pay the entire costs. This provision was later changed so that employees would only pay a $\$ 100$ filing fee based on subsequent court decisions rejected the imposition of the costs of employer mandated nonunion arbitration procedures on employees.

As noted above, an interesting feature of the company directive is that it left the format of the procedure up to the division. Prior to the company directive on alternative dispute resolution procedures, the individual divisions of TRW had a variety of internal complaint procedures. These ranged from simple open door policies to the complex peer review procedure in the VSSI division described above. The company directive led to both the introduction of new arbitration procedures and a coincident enhancement of many of the internal complaint procedures. These collateral changes in internal complaint procedures reflect an interesting process in which the focusing of organizational effort on improving existing dispute resolution procedures led to changes beyond those that inspired the initial initiative. This suggests that organizational change is not a continuous process of adaptation to environmental pressures and internal imperatives, but rather that there is a discrete process in which the forces that overcome organizational inertia in a particular area can lead to a series of attendant changes.

One of the divisions that introduced more general changes to its dispute resolution procedures in conjunction with the introduction of nonunion arbitration was TRW's Systems 
Integration Group (SIG). Prior to the introduction of arbitration, SIG had a simple grievance procedure in which employees could lodge written complaints with senior management, who would either accept or reject the complaint. Accompanying the introduction of arbitration, SIG established a new three-stage dispute resolution procedure. The first stage, "management review" consisted of the internal complaint procedure. The employee would begin the first stage by presenting a written statement of the dispute to the immediate supervisor.

If unresolved, the next part of stage one would be for the complaint to be reviewed by a higher-level manager who had not been involved in the decision that was the subject of the complaint. During these two parts of stage one the facility's human resources manager would provide internal mediation to try to resolve the dispute. If unresolved, the employee could take the dispute to stage two, "appeals committee/mediation", which provided two mutually exclusive options. In the first option, the complaint could be reviewed by an appeals committee, consisting of a five member panel of fellow employees with the senior human resources director serving as a non-voting chair. The appeals committee was a peer review type of panel, though unlike the randomly selected VSSI panels, in SIG employees could nominate their fellow employees to serve on the pool from which the committee is drawn. The employee selected three members from the pool and management selected the remaining two. The other option in stage two was to have the complaint brought to an external mediator who would attempt to facilitate a negotiated resolution of the complaint. As will be discussed later, after a period of experience with the procedure, stage two was modified to eliminate the appeals committee option due to lack of employee usage. If the complaint was unresolved at stage two, the employee could proceed to stage three "alternative dispute resolution". Where the employee selected the appeals committee 
option in stage two, they were required to participate in external mediation as an initial part of stage three. If the complaint was unresolved in mediation, the final part of stage three was arbitration. The arbitrators are chosen from American Arbitration Association lists of employment arbitrators.

For disputes involving allegations of sexual or racial harassment or termination, the employee had the option to bypass stage one and/or stage two. Disputes involving discipline for violation of sexual or racial harassment policies or legal and ethical conduct policies had to be taken directly to stage three mediation and arbitration. The inclusion of the appeals committee and mediation options in the SIG procedure is particularly noteworthy. The combination of appeals committees and mediation provide an additional dispute resolution structure within the division that goes beyond the basic nonunion arbitration procedure required under the company directive to help shield against litigation. As will be described in more detail below, these additional new institutional structures may have particular importance for the process of resolving disputes within the firm.

The other divisions of TRW adopted a range of combinations of elements in their procedures. In contrast to the multi-stage procedure at SIG, with its appeals committee and mediation options, the procedure introduced for staff at TRW corporate headquarters simply provided for arbitration of legal claims. Within the Automotive group, the Valve Division introduced both peer review and arbitration procedures in response to the corporate directive. Whereas at VSSI, the division adopted a similar approach to SIG and introduced mediation and arbitration as additional stages to its dispute resolution procedure, supplementing its existing peer review panel procedure. 
Although the automotive business group has a larger workforce, employees within the SDIT group made greater use of the new mediation and arbitration procedures. During the first three years after the introduction of the new procedures, from 1995 to 1997, out of a total of seventy-two mediation and arbitration cases at TRW, fifty-five were in the Space, Defense, and Information Group. The vast majority of these claims were either resolved or abandoned during or after the mediation stage, with only three of the seventy-two claims during this initial threeyear period going to arbitration. A range of different types of cases were brought to mediation and arbitration during this period, including: 27 layoffs involving employees in protected groups; 20 wrongful discharge claims of all types; 7 disputed applications of company policies or discipline short of termination; 5 Americans with Disabilities Act claims; 5 claims of sexual harassment or discharges for sexual harassment; 4 promotion denials or demotions; 2 Equal Pay Act claims; and 2 failures to rehire following layoffs.

With the majority of claims being resolved or abandoned at mediation, this stage assumed particular importance in the impact of the new procedure. The experience with mediation was very positive for management, with most cases being resolved quickly and at low cost in mediation. Time to resolve cases in mediation averaged only 3-4 months from the filing of the initial claim. The average cost to management of resolving cases in mediation has been remarkably low, at around $\$ 2000$ per case. However, this figure is based on the direct monetary costs of settlements to the company, which does not include indirect costs to the company and often understated the value of the remedy to the employee. A number of the settlements in mediation involved non-monetary remedies. Reinstatement of terminated employees, adjustment of the application of policies, and finding new jobs for employees within the company were 
common non-monetary elements in settlements that provided substantial benefits to complainants without direct monetary costs to the company.

Employees used attorneys in mediation in only around half of the cases. This may reflect an employee perception that they did not need representation at this stage in the procedure or that it was to their advantage to resolve their complaint quickly and cheaply without incurring the additional expense of an attorney. However it is also possible that employees may have felt that bringing an attorney into the proceedings would be viewed as overly confrontational and negatively affect their future career in the company. Whatever the motivation of the employees, it is of concern that employees may have been settling potential legal claims in mediation without the benefit of consultation with legal counsel.

An interesting additional development in the area of representation is that a number of complainants brought representatives other than counsel with them to mediation. In some cases, spouses accompanied the complainant to mediation. In one instance, the complainant's priest attended mediation to assist the employee. Although it is difficult to judge the effect of these non-attorneys on the mediation process, they introduce a new and potentially significant element into the dynamics of the dispute resolution procedure. In many cases these non-attorney representatives were very forceful in pressing the complainant's position at mediation, more so than the complainants themselves.

In addition to the direct resolution of cases, the introduction of mediation and arbitration had important effects on the management of employment relations at TRW. For the in-house labor and employment counsels it led to a shift towards sending more of their time on proactive work and less reacting to developments in litigation. One attorney described having shifted from 
spending 60 percent of working time before the introduction of the procedures on litigation of cases, to spending 80 percent of working time after their introduction on counseling managers and helping human resources deal with employee complaints. A major part of shifting to a more proactive focus was the ability to respond to disputes more quickly. The past experience of the company had been that cases would take a couple of years to come to trial, by which point the manager involved might have left the firm. The company might also have initially accepted the manager's account of events, but then subsequently it was demonstrated at trial that the manager was engaged in illegal conduct and the manager's behavior had continued on unchecked for the interim period causing further harm and mounting damages. With less than a year being taken to bring cases to mediation and arbitration, the company was able to take remedial action more quickly and managers were more likely to be promptly held responsible for the consequences of their actions.

\section{$\underline{\text { Analysis }}$}

The development of peer review and nonunion arbitration procedures at TRW were the product of a combination of external pressures and internal management decisions that led the company to establish these new structures governing employment relations within the firm. Institutional environmental pressures and management strategies are often seen as alternative explanations for the development of organizational structures and practices. Yet in this instance, the factors of environmental pressures and management strategies worked together in determining the direction of development of procedures. In a period of declining unionization, deregulation, and globalization, institutional forces are often viewed as being of diminished 
significance in determining the content of employment relations, particularly in the United States. However it is striking that in the case examined here, which involved a company that is in many respects an exemplar of a 'High Performance' or 'High Commitment' approach to managing the workforce, institutional pressures played an important role in shaping organizational practices. Furthermore, this was not only the case in the 'old' industrial context of automobile parts manufacturing where unions still have a substantial pressure, but also in the 'new' context of the high tech aerospace sector where litigation pressures create a similar disciplining pressure on management to that of unions in the older context.

Yet it would also be incorrect to solely emphasize the institutional pressures involved and downplay the significance of management strategies. Neither union organizing nor litigation threats necessitate one specific response from management; in either case there was a range of responses the company could take. In each instance, the particular response to the environmental pressure that management chose was a product of the company's overall human resource strategy. In the context of the potential for union organizing activity, the choice of practices such as the adoption of peer review procedures provides a union substitution approach that fits with a high commitment strategy, as opposed to the alternative of simply relying on suppression of organizing drives. Similarly, in adopting an alternative dispute resolution procedure to respond to litigation pressures, the company could have taken an approach of simply requiring employees to arbitrate claims and designed a procedure that lacked significant due process protections. In this case, the decisions to introduce more elaborate procedures with a major mediation component and, especially, to make the arbitration procedure non-binding for the employee were a product of the desire to balance protection of the company from litigation 
with a human resource strategy that emphasized fostering high commitment and trust levels with its workforce.

Whereas there is a strong common thread in the interaction of environmental pressures and management strategies in the development of the peer review and nonunion arbitration procedures, the most striking contrast in this study involves the dynamics of procedures for white-collar and blue-collar employees. Even though the study examined employees within the same company with a common orientation to human resource strategy, the patterns of development and usage of dispute resolution procedures were distinct and different. For the blue-collar employee workforce in the automotive group, the dominant environmental pressure was the threat of union organizing, with litigation by employees playing no significant role. By contrast, for the white-collar employee workforce in the SDIT group, employment litigation was the dominant environmental pressure, with union organizing threats being non-existent and irrelevant. The contrasts in types of environmental pressure produced different directions of development of dispute resolution procedures to respond to the specific nature of the threat involved. To respond to the increase in litigation activity among the white-collar workforce in SDIT, adoption of the nonunion arbitration procedures provided a mechanism to transfer these claims into an alternative dispute resolution structure that could produce faster and cheaper resolution of claims, while substantially reducing the threat of the uncertainties inherent in the jury-driven litigation system. In contrast, in responding to the threat of potential union organizing and related employee expectations for fair treatment among the blue-collar employee workforce of the automotive group, peer review procedures provided a mechanism for employee involvement in the area of dispute resolution that could offer a better alternative to union 
grievance procedures than simple management decision-making in responding to complaints.

The contrast between white-collar and blue-collar employee groups in the development and structure of dispute resolution procedures was also reflected in how the procedures were used. Although peer review procedures were available to both blue-collar and white-collar employees in the automotive divisions where it was adopted, in practice it was used almost exclusively by blue-collar employees. Even more strikingly, when peer review was offered as an option that could be used instead of mediation in the procedure adopted for the SIG division's white-collar workforce, the peer review option was used so infrequently that the option was later dropped from the procedure. The explanation offered within the division for this lack of usage of the option was that the white-collar employees perceived that mediation would provide them with a more independent dispute resolution processes than peer review. One of the particular concerns with peer review for many white-collar employees is that their effective peer group includes employees who are in management or on career tracks leading into management. If the peers on the panel bring a managerial perspective to the dispute resolution process, much of the distinctiveness of peer review compared to a grievance procedure in which a board composed entirely of managers hears the complaint is lost. This difference has broader implications when we consider the differing nature of employment relations for white-collar and blue-collar employees. Traditionally industrial relations theory and research has emphasized a sharp divide between labor and management as two separate actors in the industrial relations system. In the nonunion context studied here this analysis held up well in looking at the blue-collar employee workforce, but broke down in looking at the white-collar employee workforce where the employees did not necessarily identify with their fellow employees as a group with common 
interests in opposition to managers within the company. For these white-collar employees, external mechanisms of the courts and independent neutrals in dispute resolution provided the supporting institutional structure for them to further their interests, rather than a structure internal to the workforce of the company such as organization either in the stronger institutional form of a union or in the weaker institutional form of worker participation in peer review procedures.

Two major criticisms that have been leveled at nonunion dispute resolution procedures are that they are lacking in due process protections and that usage of them by employees tends to be at very low levels. If the TRW procedures represent a 'best case' example among current nonunion procedures, what does it tell us about these criticisms? In the area of due process protections, the most negative picture of nonunion procedures is not supported by this study. In both the peer review and nonunion arbitration procedures, substantial protections are included to enhance the neutrality of the decision-makers, ranging from the jury-like selection procedures for peer review panelists to the use of arbitrators and mediators provided by reputable neutral service providers. Balanced against the features aimed at ensuring neutrality of decision-making is the reality that these are procedures structured by management that limit how far decisions can go in affecting organizational rules and procedures. Types of complaints are limited under both types of procedures, with nonunion arbitration and mediation restricted to potential legal claims and peer review to disciplinary and dismissal decisions that are alleged to violate company policies and procedures. An area of concern particular to the peer review procedures is limitations on the ability of parties to bring representatives to the panel hearings. Although this restriction applies equally to the supervisor who made the decision being challenged, the absence of employee representatives is a significant weakness from a due process perspective. In general, the overall 
picture of the procedures is one of a reasonable degree of due process protections, but at the same time with some substantial limitations on the procedures designed to protect the company.

When we turn to the usage of the procedures, the more dire pictures of nonunion procedures again appear unwarranted. Employees used both the peer review and nonunion arbitration procedures to a substantial degree, albeit at a rate well below usage of many union grievance procedures. Although employee win rates were not high under the peer review procedures, employees continued to use them frequently and in a number of cases where management decisions were overturned were able to continue successful careers with the company. Indeed compared to the unionized context, the relatively low win rates in the peer review procedures may be somewhat misleading given that there is no effective check on the ability of an employee to file a complaint. Whereas unions typically undertake an evaluation of the strength of a grievance in deciding whether or not it is worth taking the complaint to arbitration, under peer review the employee alone decides whether or not to proceed. Given peer review is a relatively quick and low cost procedure for the employee it is unsurprising that employees would be willing to take a chance on bringing relatively weak complaints to peer review whereas a union might not consider it worth investing the costs of arbitration on a similar weak grievance.

It is important to recognize that the most significant effects of these types of dispute resolution procedure may lie in their impact on the general conduct of employee relations by management, rather than on the resolution of specific cases. In this regard, it is noteworthy that some of the strongest concerns about the introduction of peer review came from line management concerned about having their decisions challenged and reviewed by the panels. 
Indeed, managers noted that one of the main impacts of the adoption of the peer review

procedure was to increase the time and care taken in reaching and executing decisions to discipline and dismiss employees. Viewed from this perspective, the procedures served as a tool for human resources within the organization that helped ensure line managers were actually following the policies adopted by the company directed at ensuring fair treatment of employees in the workplace. The nonunion arbitration procedures had a similar impact on helping promote fairer treatment of employees by managers, particularly due to the more rapid resolution of complaints. Given that a manager was likely to have his or her decisions reviewed in a much shorter time frame than had previously been the case, the probability that improper actions would come to light and be remedied was increased. On a broader level, an interesting development was that in some instances employee complaints under the procedures led to modification and improvement of organizational practices and procedures. For example, following a complaint that indicated a weakness in an employee relocation policy, the policy was changed to fix the problem, improving the assistance provided to employees. This occurred even though the procedures themselves specified that decisions could not modify company policies and suggests the utility of the procedures as organizational learning systems for nonunion organizations through which complaints reveal problems and weaknesses in policies and practices that might not otherwise be identified.

\section{Conclusion}

This case study set out to investigate the adoption, structure, and function of dispute resolution procedures in the nonunion workplace. The case examined here does not represent the 
situation in the typical nonunion workplace, rather it was selected as a 'best practice' case study to investigate a stronger example of the development of this type of procedure and to see the possible direction of developments in this area. One of the motivations for this investigation was to consider the degree to which nonunion dispute resolution procedures have the potential to provide some element of fairness and voice in the context of a workforce where union representation has declining reach. The answer from this study is that nonunion procedures can serve a partial function in enhancing fair treatment and employee voice in the workplace, but the degree to which they will serve this function is conditional on both the continued existence of external institutional pressures that provide an incentive to companies to adopt procedures and the strategic orientation of nonunion companies in managing their workforces. The absence of either factor will reduce the probability of the development of effective dispute resolution procedures in the nonunion workplace. It is significant that even in this setting of a 'best practice' case where the human resource management orientation of the firm was likely to be especially focused on ensuring fair treatment in the workplace, environmental pressures from litigation and unions provided the initial impetus for the introduction of the nonunion procedures. If environmental pressures are a key factor in the adoption of nonunion procedures in the 'best practice' case setting where we would expect human resource management strategies to play a stronger role, then we should anticipate that environmental pressures will be even more critical for ensuring fair treatment in the more typical 'non-best practice' nonunion workplace.

A second lesson from the study is that promoting effective nonunion procedures requires different factors for different parts of the labor force. Whereas an institutional solution of promoting the continued vitality of union representation and collective bargaining is clearly of 
importance for the blue-collar labor force, other solutions, in particular a robust litigation system combined with alternative dispute resolution mechanisms that enhance rather than undermine rights, are necessary to deal with the problems of white-collar segments of the labor force. For industrial relations research and theory this suggests that while the traditional ideas of ensuring strong institutions in the governance of employment relations remain relevant, they need to be adapted and applied to different types of solutions if they are to be effective across the whole labor force rather than one segment of it. A similar challenge is posed from an industrial relations perspective in the findings from this study that while these nonunion procedures clearly have their weaknesses and limitations, they also are serving an important role for nonunion employees within the organization in giving them a structure that can be used to challenge unfair decisions and helping to shape how managers deal with employees in the workplace. Although not a strongly institutionalized structure for governance of employment relations of the form seen in American unionized workplaces with their collective agreements and grievance arbitration procedures, neither does this appear as a situation of unchecked managerial discretion. Rather the combination of external pressures and the company's development of an internal institutional structure through these dispute resolution procedures creates a situation that can be described as a semi-institutionalized structure for governance of employment relations. If this type of semi-institutionalized structure is viable and effectively excludes external actors such as national unions from the workplace, then it poses a major challenge to the conventional industrial relations system based on strongly organized workplace representation through collective bargaining. Questions that will need to be answered in relation to the development of this type of semi-institutionalized governance structure include: how sustainable are these 
procedures; how widely will they diffuse across different organizations; and what is the role of employee representation in relation to these procedures? For the union movement, this last question will be particularly critical if they are not to abandon prospects for providing representation across a growing segment of the labor force.

Afternote: Subsequent to the period covered by this study, in 2002 TRW was acquired by the major aerospace company Northrop-Grumman. While the former TRW Space, Defense, and Information Technology (SDIT) group became part of Northrop-Grumman, the TRW automotive parts group became an independent firm under the name TRW Automotive. The implications of the acquisition and division of the company for the future of the dispute resolution issues described in this study are yet to be determined, though the shift in corporate ownership may not mean a drastic shift in approach to employee relations. Northrop-Grumman is itself known for its longstanding nonunion grievance procedure that has used arbitration as its final step since the 1940s, so it is by no means clear that the acquisition will result in a major shift in the character of the procedures in the former SDIT group. However, the potential impact of this corporate acquisition is a reminder of the importance of both management strategies and firm history in determining the path of evolution of employment relations within organizations. 


\section{$\underline{\text { References }}$}

Barringer, M.W., and G.T. Milkovich. 1998. "A theoretical exploration of the adoption and design of flexible benefit plans: A case of human resource innovation." Academy of Management Review, 23(2): 305-324.

Boxer, Jonathan. 2000. "Arbitration/Peer Review of Statutory Employment Claims: What are the Companies Doing?" Presentation at Alternative Dispute Resolution in the Employment Arena, 53 ${ }^{\text {rd }}$ Annual NYU Conference on Labor, New York University School of Law, New York, NY.

Edelman, Lauren B. 1990. "Legal environments and organizational governance: The expansion of due process in the American workplace." American Journal of Sociology, 95: 1401-1440.

Edelman, Lauren B., Steven E. Abraham, and Howard S. Erlanger. 1992. "Professional construction of law: The inflated threat of wrongful discharge." Law and Society Review, Vol. 26, No. 1, pp. 47-83.

Edelman, Lauren B., Christoper Uggen, and Howard S. Erlanger. 1999. "The Endogeneity of Legal Regulation: Grievance Procedures as Rational Myth.” American Journal of Sociology, Vol. 105(2): 406-454.

Feuille, Peter, and Denise R. Chachere. 1995. "Looking Fair or Being Fair: Remedial Voice Procedures in Nonunion Workplaces." Journal of Management, 21: 27-42.

Feuille, Peter, and John T. Delaney. 1992. "The Individual Pursuit of Organizational Justice: Grievance Procedures in Nonunion Workplaces." Research in Personnel and Human Resources Management, 10: 187-232.

General Accounting Office (GAO). 1997. Alternative Dispute Resolution: Employers Experiences with ADR in the Workplace. Washington, D.C.: United States General Accounting Office (GAO/GGD-97-157 ADR in the Workplace).

Hammer, Tove H., and Robert N. Stern. 1986. "A Yo-Yo Model of Cooperation: Union Participation in Management at the Rath Packing Company." Industrial and Labor Relations Review, 39: 337-49.

Jacoby, Sanford M. 1997. Modern Manors: Welfare Capitalism since the New Deal. Princeton, N.J.: Princeton University Press.

Kochan, Thomas A., Harry C. Katz, and Robert B. McKersie. 1994. The Transformation of America Industrial Relations. Ithaca, NY: ILR Press.

Lewin, David. 1987. "Dispute Resolution in the Nonunion Firm: A Theoretical and Empirical Analysis." Journal of Conflict Resolution, 31(3): 465-502. 
Lewin, David. 1990. "Grievance Procedures in Nonunion Workplaces: An Empirical Analysis of Usage, Dynamics, and Outcomes." Chicago-Kent Law Review, 66(3): 823-844.

Olson-Buchanan, Julie B. 1996. "Voicing discontent: What happens to the grievance filer after the grievance?" Journal of Applied Psychology, Vol. 81, No. 1, pp. 52-63.

Rubinstein, Saul A., and Thomas A. Kochan. 2001. Learning from Saturn: Possibilities for Corporate Governance and Employee Relations. Ithaca, NY: ILR Press.

Schwartz, Roger M. 1994. The Skilled Facilitator. San Francisco, CA: Jossey-Bass.

Slichter, Sumner, James J. Healy, and E. Robert Livernash. 1960. The Impact of Collective Bargaining on Management. Washington, D.C.: The Brookings Institution.

Stone, Katherine V.W. 1996. "Mandatory Arbitration of Individual Employment Rights: The Yellow Dog Contract of the 1990's." Denver University Law Review, Vol. 73, pp. 1017-50.

Stone, Katherine V.W. 1999. "Employment Arbitration Under the Federal Arbitration Act." Chapter 2 in A.E. Eaton and J.H. Keefe, eds., Employment Dispute Resolution and Worker Rights in the Changing Workplace. Champaign, IL: Industrial Relations Research Association. 